Walfrido C. Adan, Jr., MD

Department of Otorhinolaryngology Head and Neck Surgery Quezon City General Hospital
Correspondence: Dr. Walfrido C. Adan, Jr. Department of Otorhinolaryngology

Head and Neck Surgery

Quezon City General Hospital \& Medical Center

Seminary Road, Brgy. Bahay Toro

Project 8, Quezon City 1106

Philippines

Phone: +63093 28808749

Email: zandromd@gmail.com

Reprints will not be available from the author.

The author declared that this represents original material that is not being considered for publication or has not been published or accepted for publication elsewhere, in full or in part, in print or electronic media; that the manuscript has been read and approved by the author, that the requirements for authorship have been met by the author, and that the author believes that the manuscript represent honest work.

Disclosures: The author signed a disclosure that there are no financial or other (including personal) relationships, intellectual passion, political or religious beliefs, and institutional affiliations that might lead to conflict of interest.

\section{Tracheal Re-Stenosis after Resection and Anastomosis of Complete Tracheal Stenosis}

Tracheal stenosis is a difficult complication to treat. It begins as a complication and eventually becomes serious enough to compromise the airway leading to surgery. The treatment of complete tracheal stenosis is resection with tracheal end-to-end anastomosis. ' The incidence of tracheal re-stenosis following anastomosis is relatively high at about $10.5 \%$ for Caucasians. ${ }^{2}$ We are not aware of any studies on the incidence of this condition in the Philippines.

In airway management, endotracheal intubation is the initial choice to secure the patient's airway followed by tracheostomy tube insertion. Both modalities require proper weaning for eventual decannulation. If decannulation has failed, the possibility of tracheal stenosis as a complication must be considered and investigated.

In cases of re-stenosis after tracheal resection and anastomosis, what to do next is a challenge. Should another surgery for resection be planned? Will there be any changes in the technique of the surgery or additional medical treatment? Answering these questions may guide the surgeon's next move and prevent re-stenosis and ultimately lead to decannulating the patient.

We present a case of tracheal re-stenosis following two separate tracheal resections and endto-end anastomosis procedures.

\section{CASE REPORT}

A 33-year-old man was admitted twice at our institution; initially four years ago for a cerebro vascular accident (CVA) when he was confined in the Intensive Care Unit (ICU) and an endotracheal tube was inserted. The patient was medically managed for three weeks and was subjected to repeated re-intubation three times due to inadvertent extubation and mucus plugs.

On the $21^{\text {st }}$ hospital day, he was referred to our service for tracheostomy due to prolonged intubation, and a $1 \times 1 \mathrm{~cm}$ tracheal window was created over the anterior portion of the third tracheal ring.

The patient's general condition improved and on the $21^{\text {st }}$ post-tracheostomy day, decannulation was scheduled. However, upon occlusion of the tracheostomy tube, no escape of air from the upper airway passages was noted. Imaging and visualization confirmed a tracheal stenosis above the cannula at the level of the second tracheal ring. The thickness was noted to be approximately $8 \mathrm{~mm}$ to $12 \mathrm{~mm}$. (Figures $1-3$ )

The complete tracheal stenosis was excised with end-to-end anastomosis. The second, third tracheal rings were removed along with the granulation tissue and stenosis. The patient was discharged after 18 days. At home, he complained of difficulty breathing when using the fenestrated tube until he was eventually unable to tolerate the fenestrated tube and became aphonic. He did not consult during this period. 

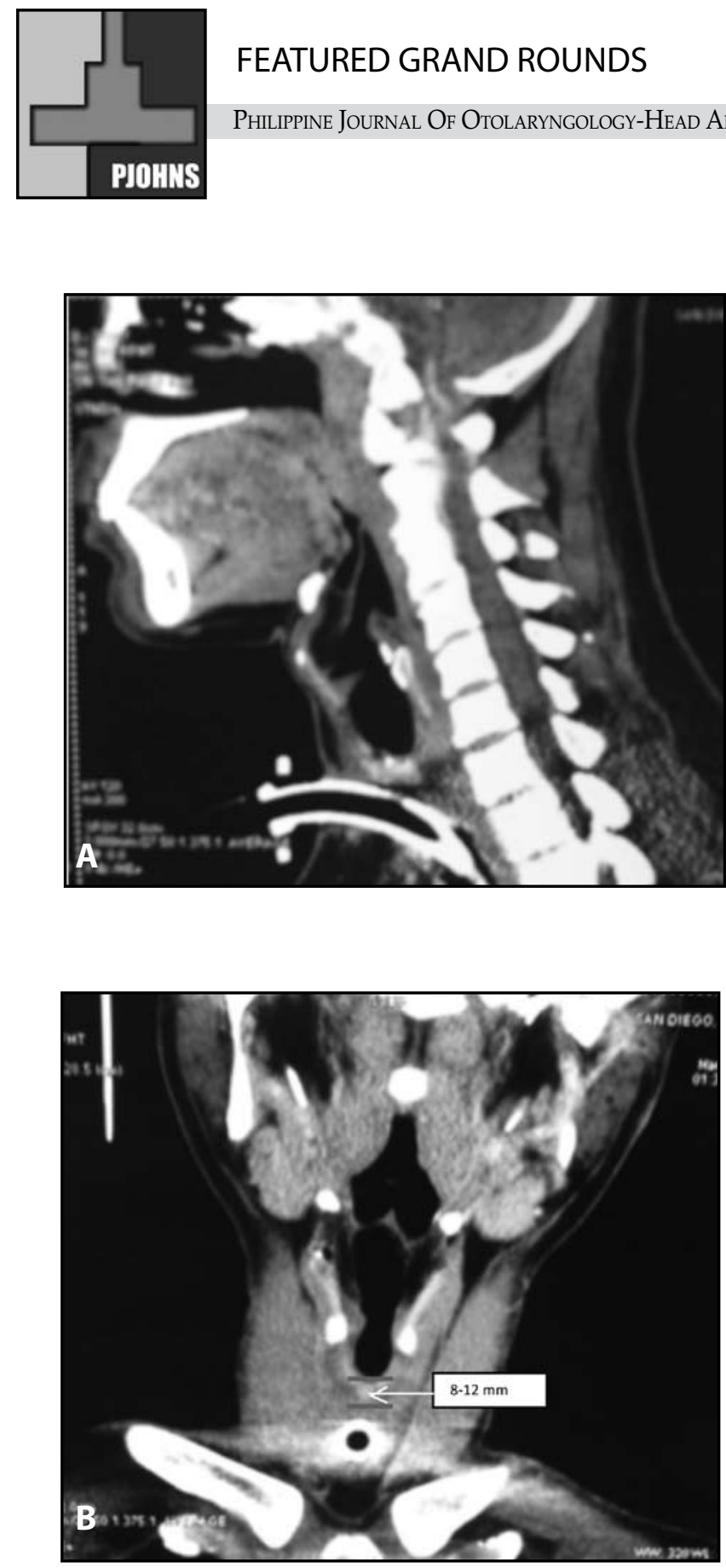

Figure 1. Plain CT Scan, A. sagittal and B. coronal views showing 8-12 mm suprastomal stenosis prior to resection.

Four years later on follow-up, a recurrence of the complete tracheal stenosis was noted. (Figure 4) He was re-admitted for a second tracheal resection with end-to-end anastomosis. The second tracheal ring and stenotic portion were removed. This second tracheal ring now corresponded with the patient's actual fourth tracheal ring. A total of three tracheal rings had been excised, approximately $3-4 \mathrm{~cm}$ in length, since the first resection. The post-operative course was uneventful and the patient could use the fenestrated tube with good voice. He was discharged after 15 days with out-patient decannulation planned.

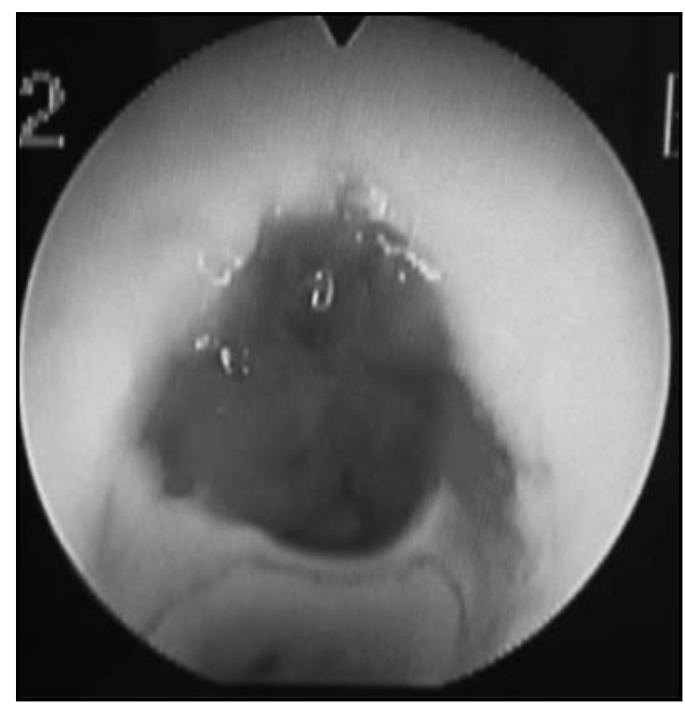

Figure 2. Trans-oral endoscopic view using a rigid 70 degree $4.0 \mathrm{~mm}$ Berci-Ward laryngoscope, showing granulation tissue over the fenestration of the tracheostomy tube.

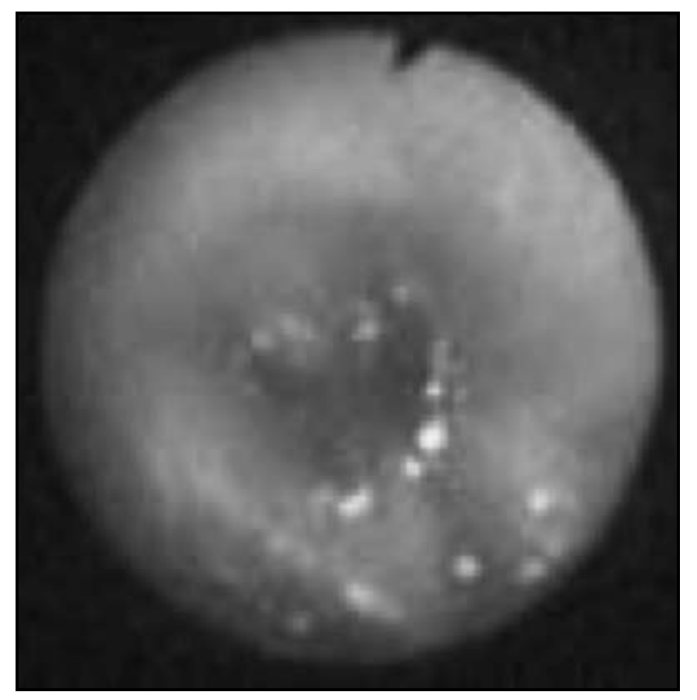

Figure 3. Trans-oral endoscopic view, rigid $90^{\circ} 4 \mathrm{~mm}$ Berci-Ward laryngoscope, after suctioning secretions, showing a funnel shaped, smooth pinkish mass completely occluding the tracheal lumen below the 1 st tracheal ring. 
FEATURED GRAND ROUNDS

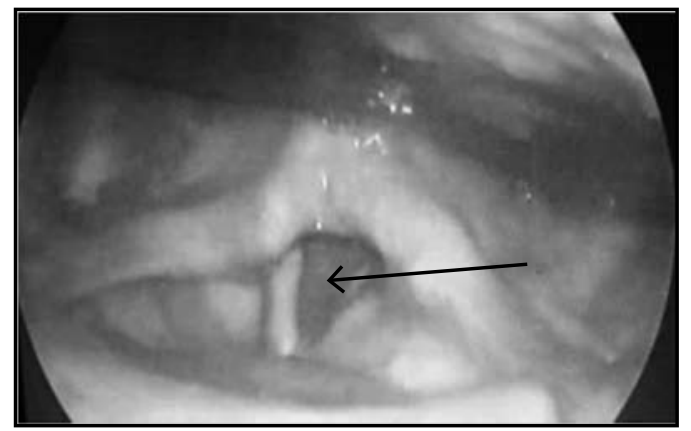

Figure 4. Trans-nasal endoscopic view, using a $4.2 \mathrm{~mm}$ flexible rhino-pharyngo-laryngo fiberoptic scope, showing a blind pouch approximately $1 \mathrm{~cm}$ below the vocal cords (arrow) prior to second resection with end-to-end anastomosis.

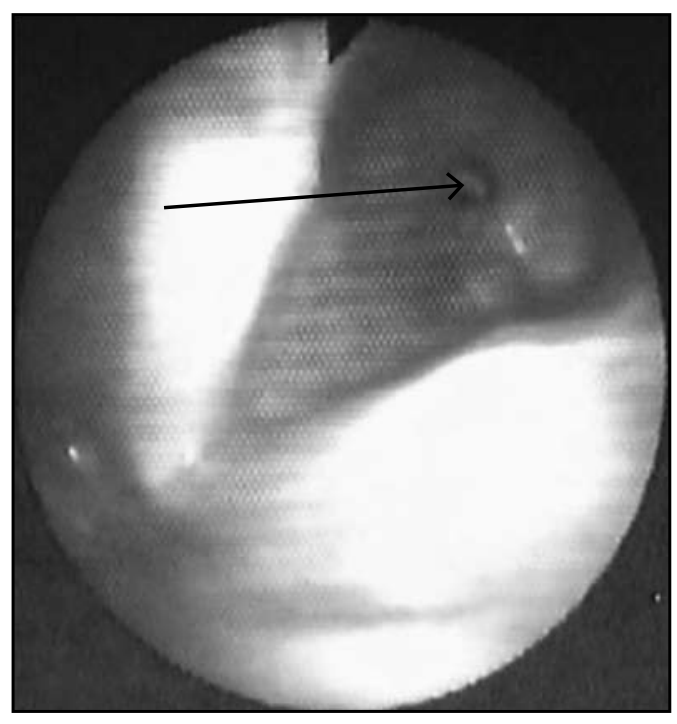

Figure 5. Trans-nasal endoscopic view using a $4.2 \mathrm{~mm}$ flexible rhino-pharyngo-laryngo fiberoptic scope, showing re-stenosis (arrow) approximately $1 \mathrm{~cm}$ below the vocal cords after second resection.

However, on follow-up two weeks later, there was note of grade III restenosis on flexible laryngoscopy. (Figure 5)

At present, the patient can still use a fenestrated tube and has a breathy voice with no stridor. Our present assessment is tracheal restenosis, membranous type, grade III, status post tracheal resection with end-to-end anastomosis (2009 \& 2013).

\section{Discussion}

Tracheal stenosis is an insidious process of inflammation, necrosis, granulation, fibrosis and contraction, bought about by pressure necrosis on the tracheal mucosa from an overly inflated tracheostomy or endotracheal tube balloon cuff. ${ }^{3}$ Prolonged intubation is also implicated in the disease process. ${ }^{2}$ Under the Myer-Cotton I-IV Grading system, ${ }^{1,4}$ our patient had complete grade IV stenosis prior to the two resection procedures with grade III (75-99\% occlusion) stenosis now.

The incidence of tracheal stenosis ranges from $10 \%-31 \%{ }^{1,2}$ The treatment for grade IV tracheal stenosis is resection with end-to-end anastomosis which is relatively successful in correcting the stenosis. ${ }^{1}$ However, the above procedure carries a $10.5 \%$ recurrence or failure rate. ${ }^{2}$ Our patient had two failed resections and the potential for a third.

In a study by Azizolah et al., 494 patients underwent reconstruction of post-intubation airway stenosis. Of the patients who had re-stenosis, length of resection $>4 \mathrm{~mm}$, tension, anastomotic infection and subglottic involvement were identified as the etiologic and pathophysiologic factors contributing to restenosis and failure of decannulation. ${ }^{2}$

In spite of the standard surgical technique used on our patient and uneventful post-operative course, re-stenosis still developed. It appears that fibrosis still developed on the background of inflammation causing the stenosis. Thus, we posit that using an ankylating agent will supress inflammation and fibrosis and arrest the process of stenosis.

In our case, because the underlying tracheal rings are still intact, the mucosal inflammation should be the target of treatment and another resection may not be indicated.

Endoscopic assisted bronchoscopy with sharp excision of the granulation and 4-quadrant/cloverleaf incisions of the stenotic mucosa could sufficiently enlarge the lumen. However, without an ankylating agent to supress the regrowth of the mucosa, re-stenosis will occur. Mitomycin- $C$ is such an agent that can be used topically to supress the growth of mucosal tissue in cases of tracheal stenosis. ${ }^{5}$ It is a novel approach and has yet to be standardized in the treatment of tracheal stenosis. ${ }^{6}$

Mitomycin- $\mathrm{C}$ is an antimitotic drug that inhibits in vitro fibroblast proliferation and can prevent the formation of scars and fibrosis in both rabbits and humans. The effects of this drug have been tested in surgical treatment for pterygium, upper urinary tract, urothelial tumors, endoscopic sinus procedures, maxillary antrostomy and dacryocystorhinostomy. ${ }^{6,7}$

A recent retrospective study showed that topical Mitomycin- $C$ is an effective adjuvant in the treatment of tracheal stenosis. At a dosage of $0.04 \mathrm{mg} / \mathrm{mL}$, it has been found to be a potent inhibitor of the vigorous granulation response seen after airway injury in animal models 


\section{FEATURED GRAND ROUNDS}

and pediatric patients. ${ }^{6}$ In another study, high dose Mitomycin- $\mathrm{C}$ at $0.5 \mathrm{mg} / \mathrm{mL}$ had a better success rate $(>52 \%$ ) than low dose $0.2 \mathrm{mg} /$ $\mathrm{mL}$. Success rates of adjuvant topical Mitomycin-C application after laser, cauterization and microdebridement vary. Microdebrider in combination with dilatation cases showed promising results. ${ }^{8}$ The same is seen with stenting. ${ }^{1}$ Laser resection with dilatation had $60-70 \%$ success rates. ${ }^{9}$ No studies could be found comparing microdebrider, laser and stenting or their combinations.

Given the many options to treat tracheal stenosis, should a repeat resection-anastomosis be done? Or should a less radical approach be undertaken to treat this patient? With all these in mind and upon the recommendation of the expert panel, we propose that the plan for this patient is 4-quadrant laser resection, application of Mitomycin-C and insertion of a stent.

\section{ACKNOWLEDGEMENT}

The author wishes to thank Dr. Rey Vencio for the patience and technical expertise he shared in the making of this featured grand rounds. The department of ORL-HNS, QCGH, headed by its new Chairman Antonio G. Talapian, MD, FPSOHNS, and Training Officer Emmanuel Tadeus Cruz, MD, FPSOHNS for direction and logistic support in the writing and presenting this case.

\section{REFERENCES}

1. Khalid AN, Goldberg D. Surgical management of upper airway stenosis. In:Flint PW, Haughey BH Lund VJ, Niparko JK, Richardson MA, Robbins KT, Thomas JR, editors. Cummings otolaryngology head \& neck surgery. th $^{\text {th }}$ ed. Philadelphia: Mosby Elsevier; 2010. P.943-52.

2. Azizollah AD, Mohammad BS, Mojtaba J, Saviz P, Abolghasem DK, Reza S, et al. Surgical treatment of post-intubation tracheal stenosis. Tanaffos. 2010 Aug; 9(4): 9-21

3. Macchiarini P, Verhoye JP, Chapelier A, Fadel E, Dartevelle P. Partial cricoidectomy with primary thyrotracheal anastomosis for postintubation subglottic stenosis. J Thorac Cardiovasc Surg 2001 Jan;121(1): 68-76

4. Myer CM 3rd, O'Connor DM, Cotton RT. Proposed grading system for subglottic stenosis based on endotracheal tube sizes. Ann Otol Rhinol Laryngol. 1994 Apr;103(4 Pt 1):319-23

5. Rahbar R, Shapshay SM, Healey GB. Mitomycin: effects on laryngeal and tracheal stenosis, benefits, and complications. Ann Otol Rhinol Laryngol. 2000 May;110(1):1-6.

6. Wong JL, Tie ST, Samril B, Lum CL, Abdul Rahman MR, Abdul Rahman JA. Successful treatment of tracheal stenosis by rigid bronchoscopy and topical mitomycin C: a case report. Cases Journal [serial on the Internet]. 2010 Sep [cited 2013 Sep 22]; 3(2): [about 3 p.]. Available from: http:// www.casesjournal.com/content/3/1/2.

7. Iñiguez-Cuadra $R$, San Martin Prieto J, Iñiguez-Cuadra $M$, Zuñiga Erranz $S$, Jofre Pavez $D$ Gonzalez Bombardiere S, et al. Effect of mitomycin in the surgical treatment of tracheal stenosis. Arch Otolaryngol Head Neck Surg. 2008 Jul;134(7):709-14.

8. Regone RM, Lambert E, Roy S. Management of acquired distal tracheal stenosis with transtracheoscopic microdebrider assisted excision and balloon dilation. The University of Texas Health Science Center at Houston. [cited 2013 Sep 28]. Available from: http://webcache. googleusercontent.com/search?q=cache:_oDkfE6aaN4J:www.triomeetingposters.org/wpcontent/uploads/2013/04/2-244.pdf+\&cd=5\&hl=en\&ct=clnk\&gl=ph

9. Zozzaro M, Harirchian S, Cohen E. Flexible fiber $\mathrm{CO} 2$ laser ablation of subglottic and tracheal stenosis. Laryngoscope. 2012 Jan; 122(1):128-30. 